\title{
Albumina sérica como marcador nutricional de pacientes em hemodiálise
}

\section{Serum albumin as nutritional marker of hemodialysis patients}

Nelma Scheyla José dos SANTOSt (in memorian)

Sérgio Antônio DRAIBE ${ }^{1}$

Maria Ayako KAMIMURA2

Lilian CUPPARI²

\section{R E S U M O}

A prevalência de desnutrição protéico-energético em pacientes com insuficiência renal crônica submetidos à terapia de hemodiálise é elevada. Dentre os diversos parâmetros disponíveis para a avaliação do estado nutricional, a albumina tem sido o mais comumente utilizado para este fim visto a sua estreita associação com a morbidade e mortalidade nesta população. No entanto, vários fatores como idade, comorbidades, hipervolemia e perdas corpóreas podem influenciar as concentrações séricas de albumina. Além disso, na vigência de inflamação, condição comumente presente neste grupo de pacientes, o metabolismo da albumina pode encontrar-se alterado, influenciando os seus níveis plasmáticos. Sendo assim, esta comunicação tem como objetivo abordar os aspectos gerais da albumina e discutir a sua utilização na avaliação do estado nutricional de pacientes com insuficiência renal crônica submetidos à hemodiálise.

Termos de indexação: albumina sérica, mortalidade, pacientes, desnutrição energético-protéico.

\section{A B S T R A C T}

The prevalence of protein-energy malnutrition is high in patients with chronic renal failure on long-term hemodialysis therapy. Among several parameters available for the assessment of nutritional status, albumin

\footnotetext{
1 Departamento de Medicina, Disciplina de Nefrologia, Universidade Federal de São Paulo, Escola Paulista de Medicina. R. Pedro de Toledo, 282, Vila Clementino, 04039-000, São Paulo, SP, Brasil. Correspondência para/Correspondence to: L. CUPPARI.E-mail: lilian@dis.com.br

2 Programa de Pós-graduação em Nutrição, Universidade Federal de São Paulo, Escola Paulista de Medicina. São Paulo, SP, Brasil.
} 
has been the most commonly used given its strong association with morbidity and mortality in those patients. However, many factors such as age, comorbidities, hypervolemia and body losses, can affect the serum albumin concentration. Furthermore, the albumin metabolism can be altered in the presence of inflammation, a common condition in this group of patients. Thus, this communication aimed to address the general aspects of albumin and discuss its usefulness for assessing nutritional status in chronic renal failure patients undergoing hemodialysis.

Index terms: serum albumin, mortality, patients, protein-energy malnutrition.

\section{N T R O D U Ç Ã O}

A prevalência de desnutrição energético-protéica em pacientes com insuficiência renal crônica em programa de hemodiálise é elevada'. A depender do parâmetro utilizado, esta prevalência pode variar de $10 \%$ a $54 \%^{2}$. Resultados obtidos pelo método da avaliação subjetiva global do estado nutricional chegam a apresentar 64\% dos pacientes em hemodiálise com algum grau de desnutrição3.

Avaliar corretamente o estado nutricional destes pacientes é um aspecto de fundamental importância, já que a desnutrição energético-protéica nesta população, é um fator de risco de morbi-mortalidade 1 . Um dos fatores responsáveis pela desnutrição energético-protéica é a ingestão alimentar insuficiente. Como esta condição leva a uma redução, tanto das reservas de gordura quanto da massa magra corporais, a procura de métodos capazes de efetivamente quantificar esta depleção é uma constante.

Diante disto, além de métodos subjetivos, como a avaliação subjetiva global, tem-se utilizado métodos objetivos, como a antropometria e marcadores bioquímicos para avaliar a desnutrição ${ }^{4}$. Concentrações séricas de albumina, pré-albumina, transferrina e fator de crescimento', também foram usadas para avaliar o estado nutricional de pacientes em hemodiálise; no entanto, a albumina é o marcador mais comumente utilizado para este fim ${ }^{5}$. Razões para isso, incluem a facilidade com que esta proteína pode ser medida e o poder da albumina como determinante de eventos clínicos nesta população.
Uma pesquisa multicêntrica, que estudou as variáveis relacionadas com a sobrevida dos pacientes em diálise, mostrou que níveis de albumina sérica inferiores a 2,5g/dL estavam associados a maior risco de mortalidade, tanto na população em hemodiálise como em diálise peritoneal ${ }^{6}$. Contudo, aspectos como alterações na sua distribuição corporal, resposta lenta às intervenções nutricionais, e o seu papel potencial como uma proteína negativa de fase aguda da resposta inflamatória, podem limitar o seu uso como único marcador do estado nutricional?. Desta forma, avaliar corretamente o estado nutricional destes pacientes é ainda um desafio a ser enfrentado pela nefrologia clínica.

Este trabalho tem como objetivo abordar os aspectos gerais da albumina e discutir a sua utilização na avaliação do estado nutricional de pacientes com insuficiência renal crônica submetidos à hemodiálise.

\section{Propriedades fisiológicas da albumina}

As propriedades fisiológicas da albumina foram reconhecidas pela primeira vez em 1837 por Ancell ${ }^{9} \mathrm{e}$, a partir de então, sua complexidade vem sendo revelada. Entretanto, o seu papel fisiológico ainda não é totalmente conhecido, despertando, ainda hoje, a curiosidade de muitos pesquisadores ${ }^{10}$.

A albumina é a mais abundante proteína plasmática, perfazendo um total de $50 \%$ das proteínas totais do soro humano. Comparada a outras proteínas, ela é uma molécula relativamente pequena, formada por uma cadeia de 584 
aminoácidos, constituindo-se em um polipeptídeo simples com um peso molecular em torno de 69000 Daltons, arranjada predominantemente em $\alpha$-hélices sustentadas e unidas por 17 pontes dissulfeto ${ }^{11}$. Uma das importantes funções da albumina é o seu papel na manutenção do volume plasmático circulante, devido ao seu peso molecular relativamente baixo e à sua alta concentração. Ela é responsável por $80 \%$ da pressão coloidosmótica, porém, sob condições de concentrações de albumina extremamente reduzidas, surpreendentemente observa-se tão somente um edema discreto, sugerindo que esta função pode ser desempenhada por outras proteínas plasmáticas ${ }^{11}$.

A albumina desempenha também, um papel na manutenção do equilíbrio ácido-básico. Resíduos de histidina presentes na estrutura da albumina, por terem um pKa em torno de 7,4, conferem a ela uma função de tamponamento em situações de acidose metabólica, enquanto que na vigência de alcalose metabólica, ela também exerce função tampão, já que é capaz de liberar seus íons hidrogênio ${ }^{11}$. Além disso, a albumina está envolvida no transporte de uma ampla variedade de substâncias fisiológicas: moléculas lipossolúveis como os ácidos graxos de cadeia longa, hormônios como a tiroxina, o cortisol e a aldosterona e pequenos íons como o cálcio, o cobre, o níquel e o zinco. Muitas drogas também se ligam à albumina, havendo competição pelos seus sítios de ligação, tanto entre elas, quanto entre as drogas e os ácidos graxos de cadeia longa. Por último, a albumina ainda atua como um reservatório de aminoácidos, contribuindo com cerca de 5\% dos aminoácidos disponíveis para os tecidos periféricos, sendo que esta oferta encontra-se aumentada na presença de algumas doenças malignas, e em situações nas quais o balanço nitrogenado é negativo ${ }^{12}$.

\section{Metabolismo da albumina}

A concentração da albumina no fluido intravascular é o resultado do balanço entre a síntese e o catabolismo. Estes processos são complexos e independentes, embora ocorram simultaneamente ${ }^{13}$.

O fígado é o único órgão capaz de sintetizar albumina. Cerca de $12 \%$ a $20 \%$ da capacidade de síntese hepática é disponibilizada para a síntese desta proteína, produzindo diariamente $150 \mathrm{mg}$ a $250 \mathrm{mg}$ de albumina por kilograma de peso corporal em indivíduos saudáveis ${ }^{11,14}$, o que consome $6 \%$ da ingestão diária de nitrogênio ${ }^{15}$. A síntese de albumina não sofre influência dos níveis séricos per se, mas depende de uma interação complexa entre a pressão coloidosmótica no fluido extracelular hepático, níveis séricos de hormônios que sabidamente estimulam esta síntese (corticosteróides, esteróides anabólicos e tiroxina), presença de citocinas pró-inflamatórias que inibem esta síntese, e estado nutricional, incluindo aí, a disponibilidade de energia, proteínas e micronutrientes ${ }^{12}$. A ingestão alimentar insuficiente causa uma redução de $50 \%$ na síntese hepática de albumina logo nas primeiras 24 horas ${ }^{15}$. Isso persiste se essa situação se prolonga. Parece que o efeito da ingestão alimentar deficiente tem um impacto maior sobre a síntese de albumina que sobre a síntese das demais proteínas produzidas pelo fígado ${ }^{16}$.

Cabe salientar que a redução da síntese depende do tempo em que for mantida a oferta insuficiente. Inicialmente, $50 \%$ a $90 \%$ dos aminoácidos que são utilizados para a síntese de albumina são oriundos da quebra das proteínas hepáticas, ao passo que, para a síntese de outras proteínas, o fígado utiliza como substrato, aminoácidos obtidos da quebra das proteínas da musculatura esquelética. Posteriormente, se o período de privação se estende, ocorre uma redução no número de mRNA responsáveis pela síntese de albumina. Este mecanismo é uma resposta adaptativa, lenta, à falta de substratos, e não é rapidamente reversível ${ }^{17}$. A oferta de energia parece ter uma importância maior que a de proteína na produção fisiológica de albumina, o que é justificado pelos mecanismos compensatórios expostos anteriormente. Portanto, mais 
que os aminoácidos, a ingestão de energia determina, mais diretamente, a síntese de albumina, ao menos sob circunstâncias fisiológicas ${ }^{18}$.

Concluído o processo de síntese, as moléculas de albumina deixam o fígado e se dirigem para o plasma ${ }^{15}$. O espaço intravascular retém $30 \%$ a $40 \%$ do total da albumina liberada, enquanto que o espaço extravascular retém $60 \%$ a $70 \%{ }^{19}$. A distribuição extravascular da albumina varia entre os diferentes órgãos. A pele, que corresponde a apenas $6 \%$ do peso corporal total, contém $11 \%$ a $18 \%$ do total da albumina corporal. Sob condições normais, a musculatura esquelética contém em torno de $15 \%$ do pool total de albumina. Por outro lado, a maioria das vísceras contém quantidades insignificantes de albumina. O fígado, por exemplo, apesar de ser o local da síntese de albumina, contém menos de $1 \%$ do pool desta proteína ${ }^{15}$. A vida média da albumina varia entre 17 e 19 dias. Cerca de $1 \mathrm{~g}$ é perdido a cada dia pelo trato gastrointestinal e $0,4 \mathrm{~g}$ é filtrado através do glomérulo renal. Porém, apenas $17 \mathrm{mg}$ escapam da reabsorção e são excretados na urina. A albumina tem uma alta taxa absoluta de catabolismo em comparação a outras proteínas plasmáticas; mas, devido à sua abundância, sua taxa catabólica fracional (pool de albumina plasmática catabolizada por unidade de tempo) é baixa ${ }^{12}$.

O catabolismo da albumina ocorre em células de muitos tecidos, especialmente nas células dos capilares endoteliais, que lisam a albumina durante o processo de pinocitose. Os aminoácidos liberados podem ser utilizados pelos tecidos periféricos ${ }^{12}$. O controle da degradação da albumina não é claramente conhecido, mas a taxa catabólica fracional pode permanecer constante apesar de grandes alterações na taxa total de degradação. Além disso, há uma redução na taxa total de degradação em resposta à queda nos níveis séricos de albumina, possivelmente como um mecanismo compensatório. Por outro lado, caso seja realizada uma administração exógena de albumina com o intuito de elevar suas concentrações a níveis supranormais, o organismo responderá com um aumento na taxa catabólica fracional, paralelamente a uma redução na taxa de síntese, o que, rapidamente, traz essas concentrações de volta aos níveis de normalidade. Durante períodos de ingestão energética e protéica insuficiente, há também uma queda na taxa de degradação absoluta que, associada à longa vida média da albumina, impede que ocorra uma queda nos seus níveis plasmáticos, mesmo após uma semana de privação ${ }^{12}$.

\section{Medida da albumina sérica}

As concentrações séricas normais de albumina encontram-se entre 3,5g/dL e 5,0 g/ $/ \mathrm{dL}^{11}$. Entretanto, o método escolhido para realizar suas dosagens exerce influência direta sobre o resultado obtido, e, portanto, sobre a análise clínica realizada a partir deste dado.

O método mais amplamente utilizado é o colorimétrico, pelo fato de o mesmo poder ser aplicado a todos os principais sistemas analíticos. Dentro deste método, destacam-se duas técnicas: o vermelho de bromocresol e o verde de bromocresol. Numerosos trabalhos mostraram que ambas as técnicas têm pouca precisão, de forma que as concentrações de albumina podem ser subestimadas quando do uso do vermelho de bromocresol ou superestimadas quando do uso do verde de bromocresol ${ }^{14}$. Na prática clínica, o método freqüentemente utilizado é o verde de bromocresol. A origem da baixa especificidade do verde de bromocresol vem sendo estudada, e resultados mostram que, ao menos em amostras com concentrações elevadas de $\alpha_{1}$-globulina, $\alpha_{2}$-globulina e frações de $\beta$-globulina, essa superestimação deve-se ao fato de a técnica do verde de bromocresol permitir que ocorra uma reação com estas proteínas, que acabam sendo interpretadas como moléculas de albumina ${ }^{20}$. Métodos imunoquímicos são, potencialmente, os métodos mais acurados para a mensuração da albumina sérica. Tem sido mostrado que a técnica da imunoturbidimetria aplicada para a dosagem da 
albumina é muito precisa e sensível e que, portanto, deve ser o método de escolha para a medida da albumina sérica ${ }^{21}$.

Fatores que influenciam as concentrações séricas de albumina são: alterações na distribuição dos fluidos corporais, condição de hidratação, perdas corporais e taxas de síntese e catabolismo. Sob condições normais, a albumina é perdida através das paredes dos vasos para o compartimento extravascular, mas a maioria retorna ao compartimento intravascular pelo sistema linfático. Alterações na permeabilidade vascular, como aquelas que ocorrem na vigência de um processo inflamatório, resultam na perda de albumina do espaço intra para o extravascular, implicando em uma rápida queda nos seus níveis séricos $^{12}$. Além disso, em situações clínicas caracterizadas por distúrbios no volume plasmático corporal, tais como desidratação aguda, gestação, insuficiência cardíaca congestiva, insuficiência hepática e insuficiência renal, as concentrações de albumina apresentam-se alteradas, portanto, para interpretação adequada desses valores, essas condições devem ser consideradas ${ }^{12}$.

\section{Albumina em pacientes submetidos à hemodiálise}

A albumina é uma das variáveis mais freqüentemente utilizada nos índices prognósticos. Numerosos estudos têm demonstrado uma associação entre hipoalbuminemia e complicações em pacientes hospitalizados ${ }^{22}$.

Baker et al. ${ }^{23}$, identificaram três problemas fundamentais no uso da albumina sérica como uma medida objetiva do estado nutricional:

1) dificuldade, ou até mesmo, impossibilidade, em separar os efeitos da deficiência de ingestão protéica dos efeitos mediados por enfermidades ou complicações subjacentes que afetam a distribuição, o catabolismo ou a síntese da albumina;

2) o longo período de vida média da albumina, que tem como conseqüência uma resposta lenta à depleção protéica, o que reduz a extensão da queda nos seus níveis séricos;

3) as faixas de normalidade estabelecidas para populações saudáveis expõem as mesmas ao risco de diagnóstico equivocado, já que os limites inferiores propostos são adequados, permitindo que indivíduos com desnutrição estabelecida apresentem valores séricos de albumina dentro de intervalos estabelecidos como normais.

Além disso, fisiologicamente, os níveis séricos da albumina diminuem com o avançar da idade chegando a se reduzirem em $20 \%$ nos indivíduos com idade acima de 70 anos $^{23}$.

Mesmo com todas essas limitações, o fato da desnutrição energético-protéica, indiscutivelmente, causar uma redução na taxa de síntese de albumina, permite que a hipoalbuminemia observada em pacientes em programa crônico de hemodiálise, seja interpretada, primariamente, como uma conseqüência de condições nutricionais adversas 5 . Por isso, os termos hipoalbuminemia e desnutrição têm sido freqüentemente utilizados como sinônimos na abordagem a estes pacientes, e a maioria dos autores aceita este paradigma justificando que a relação estabelecida entre hipoalbuminemia e mortalidade, em hemodiálise, tem como eixo a desnutrição energético-protéica ${ }^{4}$.

De fato, pacientes mantidos em hemodiálise crônica apresentam redução da massa muscular e as concentrações séricas de albumina se correlacionam diretamente com a creatinina nesta população. Contudo, se a desnutrição fosse a única causa da hipoalbuminemia observada no paciente em hemodiálise, poderia se esperar que a suplementação nutricional fosse efetivamente capaz de restaurar o pool de albumina nesta população, o que é de fato observado em outros pacientes desnutridos que apresentam hipoalbuminemia ${ }^{24}$. Todavia, tanto a suplementação oral quanto a nutrição parenteral intradialítica não têm se mostrado eficazes em reparar a hipoalbuminemia ${ }^{25}$. Eustace et al. ${ }^{26}$ avaliaram os potenciais efeitos de uma suplementação oral de aminoácidos essenciais em 48 pacientes hipoalbuminêmicos 
em hemodiálise, e observaram uma melhora apenas modesta nos níveis de albumina destes pacientes. Portanto, vários outros processos são aventados na tentativa de encontrar uma explicação para a hipoalbuminemia encontrada nesta população, incluindo a redistribuição da albumina no espaço intersticial, a expansão do volume plasmático, as perdas exógenas, o aumento da taxa catabólica fracional e a redução na taxa de síntese ${ }^{27}$. Kaysen et al. ${ }^{28}$, realizaram um estudo avaliando a cinética da albumina em 12 pacientes em hemodiálise crônica, 6 dos quais com albumina sérica inferior a $3,5 \mathrm{~g} / \mathrm{dL}$ e os outros 6 pacientes com albumina sérica superior a $4,0 \mathrm{~g} / \mathrm{dL}$. Comparando os dois grupos, esses autores não encontraram diferenças entre eles no que se refere ao volume plasmático ou na relação entre a massa plasmática de albumina e a massa de albumina corporal total. Portanto, a expansão do volume plasmático e a redistribuição da albumina não explicaram a hipoalbuminemia observada neste pacientes.

As sobrecargas hídricas, incluindo edemas periféricos e pulmonares, são manifestações freqüentes na população de hemodiálise, e a hemodiluição pode refletir em uma concentração reduzida de albumina ${ }^{29}$. Em um recente estudo, Jones et al. ${ }^{30}$, investigaram a relação dos níveis séricos de albumina com o estado de hidratação e o achado de uma reduzida concentração de albumina no momento pré-diálise foi atribuído à expansão extracelular de fluido.

Com relação às perdas exógenas, apenas recentemente tem sido aceito que o procedimento de hemodiálise pode causar perdas significantes de albumina. Kaplan et al. ${ }^{30}$ mostraram que algumas membranas dialisadoras tornam-se permeáveis à albumina a medida que são reutilizadas (reuso), especialmente quando esterilizadas com hipoclorito de sódio. Esses autores observaram que com a diminuição do número de reusos as concentrações plasmáticas de albumina dos pacientes aumentam. Kaysen et al. ${ }^{28}$ encontraram uma forte correlação positiva entre a quantidade de albumina perdida e o número de reusos $(r=0,58 ; p<0,001)$, sendo esta perda mais pronunciada após 15 a 20 reusos. Portanto, esses autores concluem que, se a freqüência do reuso restringe-se a menos de 20 vezes, e ainda, se o hipoclorito de sódio é omitido do processo, essas perdas contribuem pouco para a hipoalbuminemia nesta população. Por outro lado, na ausência de perdas externas, a taxa absoluta de catabolismo da albumina é igual à sua taxa de síntese, e isto é regulado pelo fígado. Entretanto, quando os níveis séricos de albumina estão reduzidos, sua taxa absoluta de catabolismo também se reduz devido à redução na taxa catabólica fracional, o que prolonga a sua vida média. Este processo preserva o poo/ de albumina. Por isso, um aumento na taxa catabólica fracional pode contribuir para a hipoalbuminemia. A taxa catabólica fracional está apropriadamente reduzida em pacientes hipoalbuminêmicos em hemodiálise, quando comparados aos pacientes normoalbuminêmicos. Portanto, os mecanismos adaptativos para preservar o pool de albumina estão intactos nestes pacientes, e o aumento do catabolismo não é responsável pela hipoalbuminemia ${ }^{28}$.

Por último, na presença de perdas exógenas de albumina ou níveis séricos reduzidos, ocorre um aumento na sua taxa de síntese. No estudo de Kaysen et al. ${ }^{28}$ referido anteriormente, a análise da cinética da albumina mostrou que pacientes normoalbuminêmicos em hemodiálise apresentavam uma taxa de síntese de albumina similar àquela observada em indivíduos saudáveis. No entanto, os pacientes hipoalbuminêmicos apresentavam uma taxa de síntese inapropriadamente reduzida, mesmo com o aumento da perda da albumina no dialisato. Assim, a redução na síntese parece ser a mais importante causa de hipoalbuminemia nesta população.

Três processos independentes têm sido implicados na supressão da síntese de albumina em pacientes em hemodiálise: a acidose metabólica, a ingestão protéica insuficiente e a inflamação. 
A acidose metabólica tem sido associada à redução da síntese de albumina em humanos. De fato, um estudo prospectivo e controlado, realizado com 36 pacientes em hemodiálise durante 16 semanas, mostrou que ocorre uma melhora nas concentrações séricas de albumina, quando há uma correção parcial da acidose ${ }^{31}$. Alguns trabalhos, inclusive, têm mostrado uma correlação direta entre bicarbonato e albumina sérica. Entretanto, não se pode afirmar que esta correção, isoladamente, seja o fator responsável pela melhora observada ${ }^{3,28}$.

A redução da disponibilidade de aminoácidos também tem sido bem aceita como causa da hipoalbuminemia em pacientes em hemodiálise. Vários estudos têm encontrado correlação positiva entre as concentrações séricas de albumina e o Equivalente Protéico do Aparecimento de Nitrogênio (PNA), ou anteriormente denominado Protein Catabolic Rate, considerado um método preciso de avaliação da ingestão protéica estimada pela geração de uréia ${ }^{5,27}$. Corroborando esses dados, Kaysen et al. ${ }^{4}$ mostraram, por meio de um estudo longitudinal, que o PNA é um determinante independente dos níveis séricos de albumina. Entretanto, tem sido sugerido que em pacientes em hemodiálise a retenção de nitrogênio é dependente da ingestão energética. Uma ingestão energética insuficiente leva a um balanço nitrogenado negativo, ainda que na vigência de uma oferta protéica adequada, enquanto que uma oferta elevada de energia aumenta a utilização protéica, proporcionando um balanço nitrogenado neutro a positivo ${ }^{32}$.

Além disso, não raro, processos inflamatórios e/ou infecciosos acometem os pacientes em terapia hemodialítica crônica. O processo inflamatório na insuficiência renal crônica parece estar associado à falência renal per se, bem como ao procedimento dialítico e às intervenções médicas e complicações. Todavia, a origem da inflamação permanece, ainda, não totalmente elucidada ${ }^{5}$. O que já está bem estabelecido é que, nestas situações, citocinas pró-inflamatórias são liberadas, e há evidências de que as membranas bioimcompatíveis possam ser uma das causas de ativação dessas citocinas ${ }^{33}$. As principais citocinas envolvidas no processo de resposta inflamatória são a interleucina-1 (IL-1) e o fator de necrose tumoral- $\alpha$ (TNF- $\alpha$ ), chamadas de iniciadoras básicas do processo. Estas duas citocinas ativam uma cascata complexa, envolvendo mais de 20 outras citocinas, além dos sistemas de coagulação e do complemento. As citocinas estimulam ou inibem a síntese de proteínas de fase aguda que, quando dosadas no soro, são utilizadas como marcadores inflamatórios. A interleucina-6 (IL-6), que é produzida em resposta à ação da IL-1 e/ou à ação do TNF- $\alpha$, estimula, no fígado, a síntese de algumas proteínas e, paralelamente, inibe a síntese de outras tantas. Por isso, essas proteínas são denominadas, respectivamente, proteínas de fase aguda positivas e negativas da resposta inflamatória ${ }^{34}$. Particularmente no fígado, a IL-6 induz a síntese de algumas proteínas como a $\alpha-1$ glicoproteína, a amilóide sérica A e a proteína C-reativa $(P C R)$, e inibe a síntese de outras proteínas como a transferrina e a albumina ${ }^{27}$. Os marcadores de resposta inflamatória mais sensíveis são o elevado nível sérico de PCR e o reduzido nível sérico de albumina ${ }^{35}$.

Pesquisas que avaliaram as concentrações séricas de $P C R$ em pacientes mantidos em programa crônico de hemodiálise, mostraram que $32 \%$ a $53 \%$ destes pacientes apresentavam valores anormalmente elevados desta proteína ${ }^{3,36}$. Kaysen et al. ${ }^{27}$ mediram durante três meses consecutivos as concentrações séricas de PCR e albumina de 115 pacientes em hemodiálise crônica, e encontraram correlações negativas entre a PCR e a albumina. Esses mesmos autores, em 2000, realizaram um trabalho também em hemodiálise, para analisar a variabilidade dessas proteínas em relação ao tempo; os resultados e mostraram que a resposta de fase aguda parece ser intermitente, e não uma condição permanente nesta população.

O estudo de Kaysen et al. ${ }^{27}$, citado anteriormente, mostra ainda que a combinação de inflamação e ingestão protéica insuficiente leva 
a uma redução significante nas concentrações séricas da albumina, já que foram encontradas uma correlação negativa entre PCR e albumina e uma correlação positiva entre PNA e albumina. Ainda neste trabalho, foi mostrado que, na presença de concentrações séricas de $P C R$ elevadas, as concentrações de albumina eram baixas, independentemente dos valores do PNA; além disso, chamou a atenção o fato de que os valores de albumina sérica abaixo de $3,5 \mathrm{~g} / \mathrm{dL}$ ocorressem apenas quando as concentrações de PCR estavam elevadas. Esses autores concluem que a PCR e o PNA são determinantes das concentrações séricas de albumina nesta população, mas que a resposta inflamatória tem um impacto ainda mais importante.

Recentemente, Kaysen et al. ${ }^{37}$ estudaram os efeitos da PCR e do PNA nas concentrações séricas de albumina de 364 pacientes em hemodiálise, durante seis meses consecutivos, e observaram que uma elevada ingestão de proteínas pode atenuar os efeitos da inflamação sobre os níveis de albumina; concluíram que a resposta inflamatória e a ingestão protéica exercem efeitos competidores sobre as concentrações de albumina nesta população.

Outro estudo recente de investigação da albumina como marcador de estado nutricional na população em hemodiálise, selecionou 40 pacientes clinicamente estáveis, com concentrações séricas normais de PCR e função hepática normal ${ }^{38}$. A albumina sérica foi mensurada pela técnica da imunoturbidimetria e, nestes pacientes em hemodiálise sem sinais de inflamação, a concentração média de albumina sérica foi de $4,3 \pm 0,3 \mathrm{~g} / \mathrm{dL}$ no grupo de pacientes eutróficos; surpreendentemente, no grupo de pacientes distróficos, com desnutrição leve/moderada segundo a avaliação global subjetiva, os valores de albumina sérica foram semelhantes ao dos pacientes eutróficos, sendo $4,0 \pm 0,5 \mathrm{~g} / \mathrm{dL}$, ou seja, dentro do limite de normalidade (entre $3,5 \mathrm{~g} / \mathrm{dL}$ e $5,0 \mathrm{~g} / \mathrm{dL}$ ). Apenas 2 pacientes desnutridos apresentaram concentrações de albumina sérica inferiores a 3,5g/dL. Este estudo mostrou uma baixa sensibilidade da albumina na identificação da desnutrição em grau leve a moderada, sugerindo que os efeitos da desnutrição em fases mais precoces sobre os níveis séricos de albumina são pequenos. Sendo assim, o uso exclusivo da albumina sérica como marcador de desnutrição nesta população pode não ser capaz de identificar a desnutrição e, portanto, protelar uma intervenção nutricional precoce.

A resposta inflamatória implica numa complexa associação de efeitos fisiológicos, imunológicos e metabólicos ${ }^{34}$. Dependendo da duração e da intensidade, este processo pode promover uma redução da massa corporal magra, o que, conseqüentemente, pode levar à desnutrição ${ }^{35}$. De fato, Stenvinkel et al. ${ }^{39}$ sugeriram que há pelo menos dois tipos distintos de desnutrição na população em hemodiálise: o "tipo 1", que estaria associado à síndrome urêmica per se, e que se apresenta na ausência de co-morbidades importantes, em que níveis elevados de citocinas não estão presentes, caracterizando-se por uma modesta redução nos níveis séricos de albumina, neste caso, causada por ingestões energética e protéica insuficientes; e o "tipo 2", com a presença de co-morbidades significativas e resposta inflamatória evidenciada pelos níveis séricos elevados de citocinas pró-inflamatórias e PCR. Esses autores recomendam que a diferenciação entre o "tipo 1" e o "tipo 2" deve ser feita para direcionar uma conduta de acordo com as características clínicas de cada tipo de desnutrição. Entretanto, eles chamam a atenção para o fato de ocorrer, eventualmente, uma sobreposição desses dois tipos de desnutrição denominada de "tipo misto", a qual pode ser encontrada em muitos dos pacientes em hemodiálise. Esta nova forma de classificação do estado nutricional de pacientes em hemodiálise vem sendo adotada por outros autores e, além disso, protocolos têm sido desenvolvidos na tentativa de propiciar melhores benefícios em resposta às intervenções nutricionais ${ }^{40}$.

O valor prognóstico e/ou diagnóstico da albumina sérica em pacientes submetidos à 
hemodiálise é atualmente o foco de discussões, já que as suas concentrações podem sofrer influências de uma gama de condições clínicas e nutricionais ${ }^{9}$. Já está bem estabelecida que a hipoalbuminemia é um importante determinante da morbidade e mortalidade em pacientes com insuficiência renal crônica ${ }^{6}$. No entanto, até o momento, não há evidências de que a correção dos seus níveis séricos possa melhorar a sobrevida dos pacientes em hemodiálise.

\section{O N C L U S Ã O}

Várias condições têm sido implicadas com o metabolismo da albumina nos pacientes com insuficiência renal crônica e em terapia crônica de hemodiálise. Estas condições, independentemente, refletem-se nas concentrações plasmáticas de albumina. Portanto, na avaliação do estado nutricional dessa população, a medida da albumina sérica deve ser considerada somente frente a uma avaliação das condições que possam alterar seus níveis séricos, como a ingestão alimentar, a hipervolemia, a acidose metabólica e o estado inflamatório.

Apesar de a albumina ter sido, até o momento, o parâmetro mais comumente utilizado como marcador do estado nutricional dos pacientes em hemodiálise, esta proteína plasmática não deve ser utilizada como critério isolado para este fim. Fica evidente, portanto, a necessidade de associá-la a outros indicadores nutricionais, tais como antropometria, composição corporal, consumo alimentar e avaliação global subjetiva, para uma avaliação fidedigna do estado nutricional desta população.

\section{REFERÊ NCIAS}

1. Hakim RM, Levin N. Malnutrition in hemodialysis patients. Am J Kidney Dis 1993; 21(2):125-37.

2. Marckmann P. Nutritional status of patients on hemodialysis and peritoneal dialysis. Clin Nephrol 1998; 29(2):75-8.
3. Qureshi AR, Alvestrand A, Danielsson A, DivinoFilho JC, Gutierrez A, Lindholm B, et al. Factors predicting malnutrition in hemodialysis patients: A cross-sectional study. Kidney Int 1998; 53:773-82.

4. Kaysen GA. Malnutrition and the acute-phase reaction in dialysis patients - how to measure and how to distinguish. Nephrol Dial Transpl 2000; 15:1521-4.

5. Yeun JY, Kaysen GA. Factors influecing serum albumin in dialysis patients. Am J Kidney Dis 1998; 32(6) Suppl. 4:118-25

6. Lowrie EG, Huang WH, Lew NL. Death risk predictors among peritoneal dialysis and hemodialysis patients: a preliminary comparison. Am J Kidney Dis 1995; 26(1):220-8.

7. Neyra NR, Hakim RM, Shyr Y, Ikizler TA. Serum transferrin and serum prealbumin are early predictors of serum albumin in chronic hemodialysis patients. J Ren Nutr 2000; 10(4): 184-90.

8. Kaysen GA, Dubin JA, Müller HG, Rosales LM, Levin NW, Hemo Stydy Group. The acute-phase response varies with time and predicts serum albumin levels in hemodialysis patients. Kidney Int 2000; 54:346-52.

9. Ancell H. Course of lectures on the physiology and pathology of the blood and the other animal fluids. Lancet 1839-1840; 1:222-31.

10. Kaysen GA. Why measure serum albumin levels? J Renal Nutr 2002; 12(3):148-50.

11. Doweiko JP, Nompleggi DJ. Role of albumin in human physiology and pathophysiology. JPEN 1991; 15(2):207-11.

12. Whicher J, Spence $C$. When is serum albumin worth measuring? Ann Clin Biochem 1987; 24:572-80.

13. Peters T. Serum albumin: Recent progress in the understanding of its structure and biosynthesis. Clin Che 1977; 23:5-12.

14. Hill PG. The measurement of albumin in serum and plasma. Ann Clin Biochem 1985; 22:565-78.

15. Rothschild MA, Oratz M, Schreiber SS. Albumin synthesis. N Engl J Med 1972; 286(14):748-50. 
16. Dionigi $R$, Cremaschi RE, Jemos $V$, Dominioni $L$, Monico R. Nutritional assessment and severity of illness classification systems: a critical review on their clinical relevance. World J Surg 1986; 10:2-11.

17. Flaim KE, Kutson SM, Lloyd CD. Direct effect of insulin on albumin gene expression in primary cultures of rat hepatocytes. J Am Physiol Soc 1985; 9:429-32.

18. Princen JMG, Mal-Basks GRB, Yap SH. Restoration effects of glucose refeeding on reduced synthesis of albumin and total protein on disaggregated polyribosomes in liver of starved rats: evidence of post-transcriptional control mechanism. Ann Nutr Metab 1983; 27:182-93.

19. Rothschild MA, Oratz M, Schreiber SS. Extra vascular albumin. N Engl J Med 1979; 301(9): 497-8.

20. Webster D. A study of the intervention of bromcresol green with isolated globulin fractions. Clin Chim Acta 1974; 53:109-15.

21. Spencer K, Price CP. Kinetic immunoturbidimetry: the estimation of albumin. Clin Chim Acta 1979; 95:263-76

22. Bottoni A, Oliveira GPC, Ferrini MT, Waitzberg DL. Avaliação nutricional: exames laboratoriais. In: Waitzberg DL. Nutrição oral, enteral e parenteral na prática clínica. São Paulo: Atheneu; 2001. p.279-94.

23. Baker JP, Detsky AS, Wesson DE, Wolman SL, Stewart S, Whitewell J, et al. Nutritional assessment: a comparison of clinical judgment and objective measurements. N Engl J Med 1982; 306(16): 969-72.

24. James WP, Hay AM. Albumin metabolism: Effect of the nutritional state and the dietary protein intake. J Clin Invest 1968; 47:1958-72.

25. Wolfson M. Use of nutritional suplements in dialysis patients. Semin Dial 1992; 5:280-90.

26. Eustace JA, Coresh L, Kutchey C, Te PI, Gimenez LF, Scheel PJ, et al. Randomized double-blind trial of oral essential amoni acids for dialyzis-associated hypoalbuminemia. Kidney Int 2000; 57:2527-38.
27. Kaysen GA, Stevenson FT, Depner TA. Determinants of albumin concentration in hemodialysis patients. Am J Kidney Dis 1997; 29(5):658-68.

28. Kaysen GA, Rathore V, Shearer GC, Depner TA. Metabolisms of hypoalbuminemia in hemodialysis patients. Kidney Int 1995; 48:510-6.

29. Jones CH, Akbani H, Croft DC, Worth DP. The relationship between serum albumin and hydration status in hemodialysis patients. J Renal Nutr 2002; 12(4):209-12.

30. Kaplan AA, Halley SE, Lapkin RA, Craeber CW. Dialisate protein losses with bleach processed polysulphone dializers. Kidney Int 1995; 47:573-8.

31. Brady JP, Hasbargen JA. Correction of metabolic acidosis and its effects on albumin in chronic hemodialysis patients. Am J Kidney Dis 1998; 31:35-40.

32. Slomowitz LA, Monteon FF, Grosuenor M, Laidlan AS, Kopple JD. Effect of energy intake on nutritional status in maintenance hemodialysis patients. Kidney Int 1989; 35:704-11.

33. Parker III TF, Wingard RL, Husni L, Ikizler TA, Parker RA, RM. Effect of the membrane biocompatibility on nutritional parameters in chronic hemodialysis patients. Kidney Int 1996; 49:551-6.

34. Bistrian BR. Role of the systemic inflammatory response syndrome in the development of protein-calorie malnutrition in ESRD. Am J Kidney Dis 1998; 32(6 Suppl. 4):113-7.

35. Bistrian BR, Mccowen KC, Chan S. Protein-energy malnutrition in dialysis patients. Am J Kidney Dis 1999; 33:172-5.

36. Stenvinkel $P$, Heimbürger $O$, Paultre F, Diczfalusy $U$, Wang $T$, Berglund $L$, et al. Strong association between malnutrition, inflammation and atherosclerosis in chronic renal failure. Kidney Int 1999; 55:1899-911.

37. Kaysen GA, Chertow GM, Adhikarla R, Young B, Ronco C, Levin NW. Inflammation and dietary protein intake exert competing effects on serum albumin and creatinine in hemodialysis patients. Kidney Int 2001; 60:333-40. 
38. Santos NSJ, Draibe SA, Kamimura MA, Canziani MEF, Cendoroglo M, Gabriel Jr A, et al. Is serum albumin a marker of nutritional status in hemodialysis patients without evidence of inflammation? Artif Org 2003; 27:681-6.

39. Stenvinkel $P$, Heimbürger $O$, Lindholm $B$, Kaysen GA, Bergström J. Are there two types of malnutrition in chronic renal failure? Evidence for relationships between malnutrition, inflammation and atherosclerosis (MIA syndrome). Nephrol Dial Transplant 2000; 15:953-60.

40. O'Keefe A, Daigle NW. A new approach to classifying malnutrition in the hemodialysis patient. J Renal Nutr 2002; 12(4):248-55.

Recebido para publicação em 21 de janeiro e aceito em 1 de setembro de 2003. 